\title{
The Use of Activity Theory in Literacy Research: Working and developing a vocational portfolio and the interaction of the two activities
}

\author{
ZOE NIKOLAIDOU
}

\begin{abstract}
In this paper, I show the relevance of using Activity Theory in the study of situated literacy. In order to do that, I draw on ethnographic data collected during a six-month period that focuses on the literacy practices of a warehouse administrator who studies on a work-basis for the completion of a National Vocational Qualification in the UK. The employee's work context and the process of studying for a qualification are examined here as two distinct activity systems, within which various literacy events are enacted and literacy practices are developed. The result is a detailed study of the interaction of these two activity systems, and it becomes clear that work practices and qualification practices are connected in many ways. One of the most important connecting factors is the vocational portfolio, which acts as a boundary object between the two distinct yet highly recontextualising activity systems.
\end{abstract}

\section{Introduction}

In this paper, it is suggested that the study of literacy as a social skill can be better understood with the help of Activity Theory (AT) as a heuristic framework. Because of its socially constructed nature, literacy is often witnessed in multi-contextual environments, where people engage with more than one parallel activity. In such cases, it is often difficult to understand and describe the multiple reading and writing processes that take place and the purposes of the texts being produced. An example of such a case is vocational education, where people are often working and studying at the same time. By examining work and vocational studies as two distinct activity systems and by performing an activity system analysis we can examine, in a more systematic way, what is going on when these practitioners/students read and write.

Literacy is understood in this paper as a contextualised activity and is examined within the framework of the New Literacy Studies (NLS). The field of NLS is central to any study of context 'since almost all contexts are in some way textually mediated' (Satchwell and Ivaniç 2007:305). In a similar fashion, AT places context at the heart of every human action. Human actions are interpreted when taking into account the elements that constitute the context of an activity system. For AT contexts are neither perceived as 'containers of behaviour', which human agency has not affected 
in the least, nor as purely linguistic and symbolic entities that can be created independently of the deeper socio-economic structures (Engeström1990). On the contrary, AT perceives context as a situation under the complete control of individuals and therefore Engeström argues that contexts are 'constructed by humans, not by superhuman agents' (1990:78). An activity system consists of one or more subjects, the aim (object) the subjects wish to accomplish and the mediating means they use in order to achieve this aim. Equally important elements are the community that surrounds and takes part (directly or not) in the activity, the division of labour between the subjects and the rules that underpin the whole system.

The study of literacy practices under the prism of AT is given a new light. At a methodological level, AT gives the researcher tools with which to analyse and interpret ethnographic data. By viewing literacy events within the framework of an activity system, it is possible to gain a clearer understanding of the actors involved in the literacy events and the aim they wish to accomplish. The concept of the community helps interpret the role of other actors that are, directly or indirectly, involved in the activity. Brandt's (1995) sponsors of literacy, for example, can be analysed as part of an activity's community and therefore provide a clearer picture of the role they play in creating and shaping literacy practices. Finally, the mediating factors of rules and division of labor have a major role to play in developing the practices of both the system as a whole and the actions of the individual. Embedding AT therefore in the study of literacy results in a more accurate contextualisation of literacy events and in a more valid interpretation of the meaning of literacy practices. It can be even argued that AT provides the researcher with the necessary tools to move from the identification of literacy events to that of literacy practices, exactly because events are not examined as isolated activities but as the part of a bigger whole.

An additional aspect of literacy research that is given new light under the use of AT is the changing nature of literacy practices. An activity system is a situation of human actions that involves multiple and ongoing contradictions and consequent expansions. One of the major principles of an activity system is historicity, the fact that every activity system has a past and possibly a future and that during its lifetime the activity has taken various forms and meanings. Studying literacy events and practices within an activity system, the researcher is given the possibility to follow the trajectory of literacy practices and, maybe more importantly, to interpret the reasons for change. The introduction of a new working system in a workplace, for example, can result in a dramatic alteration of the literacy practices drawn upon by the employees. The same can happen in the case of the introduction of new work roles or new working rules, of staff changes or even more minor changes like venue, schedule, etc. All these factors influence the development of literacy practices within an activity and therefore explain their ongoing 
changing nature. By examining therefore the use of literacy within an activity system it is possible to contextualise it not only in place but also in time and, if so wished, to trace the historic changes that literacy practices have undergone.

Earlier studies have already made a combined use of literacy research and AT. Sylvia Scribner (1997:231) argued that: 'we may conceptualize literacy as a set of activities satisfying distinctive motives related to the written language: creating distinctive genres of communication, for example, or transmitting information over time and space'. More recently, Russel (2005) found that common in the two theories are the central role of textual mediation, the situated character of local events and practices, the range of studies beyond formal schooling (e.g. in workplaces, homes, neighbourhoods, etc) and the focus on multimodal texts. In a study of the literacy practices involved in a house-building project in South Africa (Kell 2006) AT is used as the basic unit of analysis. Kell problematizes the size of an activity system and asks the question of where such a system begins and ends. In a study of the literacy practices of students in Further Education, Ivanič (2006) uses the framework of AT in order to discuss the formation and transformation of the students' identities. In a different study, Keating (2005:115) argues that identities 'are being forged in the tension between the subjectivities that emerge from the way the activity is being performed at a particular time, space and social configuration'.

The above studies have made use of AT and literacy research and have brought the two together in various ways. What could be missing, however, is a detailed description of the way situated literacy practices can be analysed within the AT framework. This is, therefore, my aim in this paper, that is, to suggest an empirical way of using these two theories of context under one common framework.

\section{The study}

The case study discussed here originates from a six-month long ethnographic study, in which I set out to examine the literacy practices drawn upon by National Vocational Qualification (NVQ) candidates when developing a competence-based vocational portfolio. What I was mainly interested in finding out was whether the literacy practices existing at the candidates' workplace had an impact upon the practices drawn upon when developing the portfolio and vice versa. The research involved an ethnographic study of two work-based NVQ candidates, who were observed and interviewed while at work and while developing their portfolios.

Here I will discuss the case of Derry, a warehouse employee who was also a candidate for an NVQ on Business and Administration. During this study, Derry had a twofold role: he was a warehouse employee and at the same time an NVQ candidate. I therefore consider Derry as the main subject 
in two distinct activities, the 'workplace activity system' and 'the qualification activity system'. Such a distinction enables me to examine the two activities in depth and to reach results concerning the interaction and interdependence of the two activities. What is important to note is that Derry's work tasks and his work on the qualification are studied here as two activities because he perceived them this way. He considered his job as a completely different process from the work he did on his NVQ portfolio, and he tried to keep the two activities separate from each other.

\section{The workplace activity system}

The activity system described here takes place in the administrative department of the warehouse and focuses on Derry, the actions he performs in order to complete his work tasks and the mediating tools he uses in order to reach this goal.

Derry was a man in his early forties working in the administration department of a warehouse. His work role involved a variety of tasks, but his main role was to receive faulty products returned to the warehouse by retailers or individual customers, and to assess their faults. He had been in this post for seventeen years and so far he had not obtained any other qualifications or degrees.

The object of an activity has been described by Leontiev (1978) as the key to understanding the activity and he has argued that the object is driven by people's needs. The object in this specific activity is to process the administrative tasks in an effective way and to ensure the good functioning of the department. Derry, as part of a larger work community, has a certain role in the activity and that is to assess the faulty products. He contributes to the common goal by performing a variety of tasks, e.g. communicating with clients, logging products in the software, assessing products, etc. At the same time, Derry has an individual object which is to complete his own tasks as effectively as possible and to respond to the demands placed on his work role. A question that could be asked here is why Derry and everyone else in the activity is interested in the good functioning of their department. This can be answered by Kaptelinin's (2005) distinction between the object and the motive of an activity. An individual motive can be identified easier than a collective one and in Derry's case it has to do with his need to keep his job and possibly advance further in it.

The semiotic and symbolic tools within an activity system mediate between the subjects and their object. When examining the mediating tools of the administrative department, a rich inventory of literacy practices drawn upon by the community members emerges. For example, a major part of Derry's work tasks involved correspondence as he exchanged letters and emails both with clients and retailers. Additionally, he worked with specialized computer software in order to document his decisions. Software 
was also used when processing the stock that was returned to the warehouse and also in order to communicate internally with other branches or with the central offices of the company.

The tools in an activity system are not restricted to signs but equally refer to the material objects present in any activity. In the administrative department, the list of material artifacts is a long one and here I take into consideration only those that Derry mentioned during our discussions. The actual products that he assessed play an important role in his everyday material encounters. The whole process of returning the products from and to the warehouse is also highly materially mediated. Apart from the correspondence, Derry used envelopes, prepaid bags and parcels, in order to complete the transfers. Other objects such as barcode scanning devices, file cabinets, shelves and boxes complete the picture of a modern and materially mediated workplace.

The community of the warehouse at a workplace is a rather extended one. Derry is just a member of a large number of staff in the administrative section of the warehouse. Some of the people who form his immediate community are his line manager, his colleagues in the administration and the retailers. All these members have different roles in the activity (division of labour), but all contribute to how it functions effectively. The community plays an important role also in shaping the literacy practices present in the activity, as a lot of the members participate in the literacy events together with Derry and therefore have an impact upon their shape and meaning. Finally, the administrative department's activity system is penetrated by rules, which influence Derry's and the other members' work practices, including literacy practices. According to Derry, new rules are introduced in the department regularly, as for example new communication systems. In the following section, I show how such new rules create contradictions and subsequent expansion in the activity and how they influence the community's literacy practices.

\section{Contradictions and expansion in the workplace activity}

The identification of contradictions within an activity system is an important analytical step. Contradictions are described by Engeström (2001:137) as: 'historically accumulating structural tensions within and between activity systems'. Contradictions are seen as having a positive impact on activity systems as they are often the cause for transformation and progress.

A basic contradiction in this workplace activity system took place every time new software was introduced for internal and external communications. In this case, all staff in the administrative department had to learn how to work on the new system and the fact that this had happened 
rather often in the last couple of years had created some frustration. When I discussed the new software with Derry, he gave me the following answer:

I wasn't fully in to it to start with and you're just learning a lot of things when you've done them a few times you start to remember and you pick it up and you get into ... and then once you get into it you get more speed up and you get more quicker and more confident in yourself [...] experience means a lot really. (Interview extract)

The process of learning was a tiresome one and Derry was initially frustrated because he did not agree with these changes. He thought the old system was more effective and therefore found it even more difficult to learn the new one. At the end, when Derry and the other members of the activity came to grips with the new system, what was previously a contradiction led to the activity's expansion. The activity was not the same anymore as a new mediating tool was introduced, which had an impact upon the division of labour, that is, on the old work structures. New social practices had developed and within them new literacy practices, as the new system required more written and less oral communication.

\section{The qualification activity system}

In this section, I discuss Derry's attempts to obtain an NVQ as a separate activity system. Even though Derry works for his qualification on a work-basis (as opposed to being a student in a vocational college), the activity is discussed as a different one from his workplace activity. This is mainly because the objects of the two activities are different and there are new members involved and new rules penetrating the qualification process. The similarities of the two activities are the focus on Derry as a member of the activity (even though new members are involved), the space where the activity is taking place and some of the mediating tools, which however have a different function in this new activity.

In this activity system, Derry is again the primary subject since he is an employee studying towards completing an NVQ in Business and Administration. A tutor visited him at the warehouse every fortnight and helped him build his vocational portfolio, which was an absolute requirement in order to obtain the qualification.

The object of this activity therefore is the development of Derry's portfolio and the possible outcome would be the certification. Derry's individual motivation for entering this activity is described here vividly:

My NVQ, I can apply for positions that before I couldn't apply for. You see, quite often you see jobs advertisements in the 
newspapers, it's all about themselves, what the work involves and then at the end of it perhaps it might say must have NVQ level 2. So obviously if you don't have an NVQ then you can't apply for that job because it's put in a direct straight way. Whereas I'll get my NVQ and I'll see an advert that says 'must have an NVQ level 2' well I'll have one, therefore I can apply for the job and go along and have an interview and perhaps I might be fortunate and get the position, whereas if I didn't have the NVQ I wouldn't even go that far. So it's another string in my bone so to speak. (Interview extract)

As the main drivers of the activity, objects tend to remain stable within activity systems. However, a shift in the object of activity is not rare and Derry's case demonstrates that within an activity new objects can be created that can co-exist together with the initial ones. The new object will be further discussed under the expansion of the activity.

The vocational portfolio that is required for an NVQ should demonstrate prior professional knowledge and experience. The texts added in the portfolio are analysed as mediating artifacts. For the portfolio, Derry had to complete two mandatory units and three optional ones. Each one of the units had a set of performance indicators and knowledge criteria for which Derry had to provide evidence. This meant a large number of texts, which Derry had to arrange in a folder. The evidence could be anything from work emails up to his descriptions of his work tasks and tutor observations. In the following extract, he describes some of the texts he had to produce as evidence for his portfolio:

He [the tutor] asked me to do various documents and printouts and screen dumps of my daily working tasks, inspections, response system, demand system so I had an illustration and then do a little write-up about it, a little caption of what both diagrams, meetings, saying that this is what I've processed, functions, defective goods, etc. And then do a brief statement about it and then after I did all these captions ... then I did storyboards of my job, [...] step by step guide really, putting into texture that somebody can read, get the gist of what I actually do on a day basis. (Interview extract)

In this extract, it can be seen that the role of literacy as a mediator for the portfolio creation is central. Derry got involved in numerous literacy events in order to produce texts that he would use as evidence for his portfolio. Even the act of putting the portfolio together was a literacy event and indeed a rather complex one. 
Oral interaction was also frequent within literacy events. Before working on each unit, Derry had a meeting with his tutor, discussed the criteria with him and clarified uncertainties. One reason for the increased role of oral communication is probably the fact that the performance indicators were not followed by any written guidelines. Therefore, interaction with the tutor was the only way that Derry could make sense of what was required of him in order to successfully complete the portfolio. In the following extract, he comments upon the written statements he was asked to create:

Yes, it was a new style of writing for me and ... it wasn't so difficult, because explaining something that I've done and I know so well [...] I'm fully aware of what I'm doing, inspections and other things, so when I come to actually writing down what I do, this is what I do. Yeah, you just flow it, I was $O K$ at doing that I was quite ... quite good. I did make several notes first of all ... I did little notes of what I did and then read through it all and then altered one or two little sentences around, so that it sounded better when actually reading $i t$. (Interview extract)

The community involved in the qualification activity system is indeed a learning community. More workers in the warehouse were working their way towards a similar qualification and the workplace could be described as a learning environment. The HR department encouraged the employees to register for qualifications and welcomed research projects, similar to mine. Derry's line manager was particularly helpful with the creation of the portfolio and gave the NVQ candidates the opportunity to work on it during work hours when necessary. In this way, even the rules of the activity were helpful mediating elements, as they enabled Derry to work on the portfolio in a more effective way. The community of this activity is extended even outside the workplace and reaches the college where Derry was registered as a work-based student. The warehouse worked closely with the college and the college tutor was familiar with the majority of the workers. In the following section, I will show how this learning community resulted in influencing the whole activity and making learning the main mediating tool and eventually the object of the activity.

\section{Contradictions and expansion in the qualification activity system}

The strongest contradiction in the qualification activity system lies between the NVQ candidates and the portfolio as a mediating tool. Even though Derry found it easy to write descriptions of his work tasks, the situation changed when he was asked to write about situations outside his familiar job routines. For the last unit of the portfolio, he had to provide 
evidence for performance indicators that were relevant to mutual respect, diversity and effective communication practices. In this case, Derry was not sure how to approach the evidence collection:

I would say things like team working and communication is relevant to my work, we should write about, but the other aspects, especially diversity and stuff, it's not ... in the job tasks, I'm doing story boards about something not being fully aware of it. (Interview extract)

In this case, Derry was asked to get involved in new literacy events. His texts would not be about situations that were familiar to him, but about new concepts and this meant that he had to do some additional work. Another way of thinking is that these concepts cannot have been new to an experienced administrator, but they were presented in a new discourse, that of performance indicators. Derry found it difficult to decipher the discourse and translate it to a language and to situations that were familiar to him.

In order to meet the demands of this unit, Derry decided to look for help outside the workplace:

on the last couple of units I have done a bit of revising and looked for a bit of help from library books [...] Yes I decided to, because I thought struggling all on my own I wasn't putting it probably in any good context, you know, professionally it's not good, so I did a little bit of studying and looked and made a few notes. (Interview extract)

Derry had started working at the library early in the process when he realised that he could not concentrate at work. He thought that his two activities (working and creating a portfolio) were separate from each other and did not like it when one took time and space from the other. The library was a good place for him because he did not have a computer at home. Later on, his eagerness to 'work professionally' on his NVQ led him to the decision to buy a computer and a printer at home:

and then I decided to get my own pc, I've got my own pc now so the going to town stopped and now I can do it in my own luxury, you know, I'm home, get a cup of tea, come home from work and I do it on the pc now. I type it at home and I found I'm doing more work now because I've got more access to it, I give a little bit more time. (Interview extract) 
Despite having a computer at home, Derry continued going to the library in order to get some help with his writing. This resulted in the development of new literacy practices, since Derry had now learned how to use the library in an effective way. According to Engeström (2001:137), expansion within an activity system is accomplished when 'the object and the motive of the activity are reconceptualised to embrace a radically wider horizon of possibilities than in the previous mode of the activity'. In this activity, Derry is dealing with new horizons as learning takes over and becomes a mediating means in itself. It is through engaging in new communicative and literacy practices that he is finally able to complete the final unit of the portfolio. Within the activity system one can distinguish new mediating means, new members in the learning community, new rules and new roles. As an inevitable result, the object is no longer just the certification. Now it has to do more with being professional and learning:

because I've studied things and looked up and revised things a little bit, it's given me more knowledge, you see, it improved me as a person and then I've done a storyboard on why communication is important and diversity and stuff like that, so each single subject has given me some knowledge of it. (Interview extract)

In an adaptation of the activity system triangle made by Ivanič, the concept of 'learning' is placed at the very heart of the triangle. Learning is described as an activity 'always embedded in the word 'doing', (Ivanič 2006:9) and the model is schematically represented in the following figure:

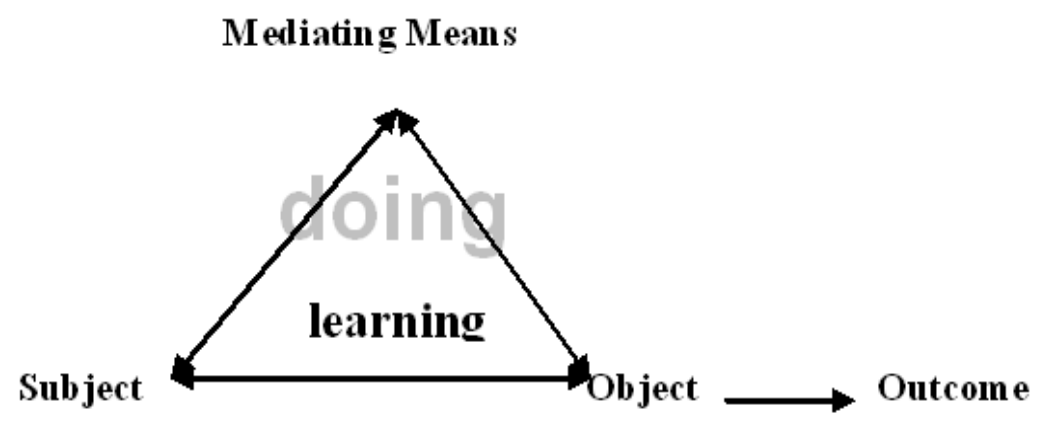

Activity System as adapted by Ivanič 2006

In Derry's case, learning constitutes the major expansion in the activity system in which he was participating. By collecting the evidence for his portfolio, or else by 'doing', he reached new levels of knowledge and new 
meanings for his work practices. As a subject in the activity, Derry used literacy related mediating means in order to achieve his object, the completion of the NVQ and to reach his wider purpose that is, the possibility to apply for a better job. Learning was not one of his initial goals in this system, but was nevertheless achieved in the process. Learning can also be explained here by Derry's participation in simultaneous activities. A different analysis would be to argue that Derry was acting within different communities of practices (Wenger 1998). Boundary crossing between multiple communities of practice, as opposed to constantly acting within one and the same community, can result in more possibilities for learning (Fuller and Unwin 2004).

The final expansion within this system took place when Derry overcame his fears about his knowledge and decided to apply for a different job:

and I made a phone call last night to jobs advertisement and it's about credit control, but I don't know what that fully involves, but it says full training it doesn't say anything about $N V Q s$, but I have got the knowledge of pc work and I've got the knowledge of the administrational things, whereas previously I didn't have that in my job role. So therefore it's given me more confidence, so I rung up last night and someone will be ringing me back this evening. (Interview extract)

The fact that Derry found the confidence to apply for a better post shows that the learning that took place in the qualification activity system had a strong influence upon the workplace activity. The interaction and interrelationship of the two activities is an issue explored in the following section.

\section{Network relations between the two activity systems}

I have examined so far two activity systems with different objects and outcomes, but with a common subject acting within them. The two activities seem to share more than Derry as an actor. They share texts as mediating means and some of the community members. However, we are indeed dealing with two separate activities, as their objects are very different: in the first case the object is work related, whereas in the second case the object is related to education and learning. The question I ask here is if and how these two activities interact. Going back to my literacy interest, I wish to know if the new literacy practices developed in each activity remain within the boundaries of the activity or if they move out of them, enter new activities and possibly change form and meaning in the process. 
The concept of polycontextuality is discussed by Engeström, Engeström, and Kärkkäinen (1995:320) as a situation where participants of activity systems engage "not only in multiple simultaneous tasks and taskspecific participation frameworks within one and the same activity. They are also increasingly involved in multiple communities of practice'. In this way, polycontextuality refers not only to actions but also to entire activity systems in which subjects participate simultaneously. In fact, some close connections have been found between AT and Wenger's (1998) communities of practice and an activity system has been described as 'a complex and relatively enduring 'community of practice' that often takes the shape of an institution' (Engeström, Engeström, and Kärkkäinen 1995).

Derry was a member of the community of practice of his workplace and more specifically of his department, since he had the same work routines and goals as the rest of his colleagues. At the same time, he was a member of the NVQ community of practice, collaborating with his tutor and colleagues towards the completion of the portfolio. Derry moved from his familiar workplace community towards the new and complex activity of vocational qualifications. 'Crossing boundaries involves encountering difference, entering onto territory in which we are unfamiliar and, to some extent therefore, unqualified' (Suchman 1994:25). For AT, boundary crossing is a consequence of contradictions and expansion inherent in the activity system. For example, there was a strong contradiction in the workplace activity, since the warehouse was soon going to close down. Consequently, Derry decided to register for an NVQ in order to more easily get a new job. The expansion of the workplace activity system led Derry to be involved in a new system, that of the qualification, where he encountered difference and was initially unqualified.

Boundary crossing takes place when subjects move across multiple activity systems and transfer tools, ideas and discourses. In Derry's case, the element most frequently transferred from one system to another is texts. The process of recontextualisation is described by Barton and Hamilton (2005:23) as texts that 'move across context, often changing their meanings and functions but nevertheless providing a fixed reference point in different events'. In the two activity systems under discussion, recontextualisation takes place with a direction from the workplace to the qualification system, as Derry uses familiar work related texts and uses them with a different meaning as evidence for his portfolio.

These texts take the role of a 'boundary object'. Boundary objects have been defined by Star (1989) as: 'objects that are both plastic enough to adapt to local needs and constraints of the several parties employing them, yet robust enough to maintain a common identity across sites'. As the texts are transferred from the workplace to the portfolio, they lose their initial function - texts used at work - and acquire a new role, that of evidence for 
the performance criteria for Derry's portfolio. Therefore these texts are plastic enough since their function changes, but they are also robust enough as their format remains the same. At the same time, the whole portfolio is also a boundary object, moving between the workplace and the learning activity. It starts as a collection of evidence of Derry's knowledge and experience but at the end it expands into something more substantive. Derry started reflecting on the textual artefacts produced at work and the practices that these communicate. The workplace texts had taken a new meaning and through the creation of the portfolio they became part of new and more meaningful literacy practices.

Polycontextuality and boundary crossing between activities often result in 'hybrid' systems. The multivoicedness and the final expansion of the two activity systems attribute them with the status of hybridity. The qualification activity system is penetrated, to a large extent, by the workplace activity system and vice versa. Derry's job role defined the NVQ he registered for and he often had to go back to his work tasks to draw evidence for his portfolio. Additionally, he later used his NVQ when applying for a job.

The hybridity of the two activities is also evident in the mediating tools that constitute them. The portfolio is a hybrid creation as it contains texts coming from a variety of sources and used for a variety of purposes. Even though Derry created certain texts only for the purposes of the portfolio, e.g. screen dumps and written statements, the portfolio would not serve its purpose if evidence from the actual work practices was not included. At the same time, the portfolio cannot stand on its own in any of the two activities. It is created within the qualification activity, but it only acquires meaning once it has been transferred to the workplace activity, as it is only there that Derry can use it as proof of prior knowledge. Therefore, hybridity penetrates most elements of both activities and defines their shape and their function.

Having as a starting point both activity systems and continuously moving across them, Derry creates a third space between qualification and workplace: 'From the perspective of activity theory, the third space might be considered an expanded activity in which the object of activity and the activity itself is reorganized, resulting in new opportunities for learning' (Gutierrez, Baquedano-Lopez and Tejeda 1999:287). The creation of a third space here takes the form of learning. Derry drew resources from both activities and became skilful in new communicative and literacy practices. These practices are likely to exit the boundaries of the two activities and accompany Derry in his involvement in new activity systems.

\section{Concluding comments}

In this paper, I have shown an example of analysing literacy practices within the analytical framework of AT. By focusing on a case study of a 
warehouse employee who creates a portfolio in order to obtain an NVQ, I have been able to discuss the uses of literacy within two activity systems and their interaction. More specifically, I have argued that literacy practices are a primary mediating tool in most activity systems, as literacy is present and plays a significant role in most expressions of current social practices. AT is useful in that is helps place literacy in a wider context, enabling the researcher to take into account factors that influence the development of literacy practices, such as the object of the activity, the rules that penetrate it, the roles that define it, and the contradictions that underpin it.

In this case study, literacy learning plays a dominant role as it takes place in the interaction between two activities. Derry developed new modes of communication brought about by his need to recontextualise some of the work texts with which he was very familiar. By entering a new activity and engaging in a learning community, he was forced to approach the same texts from a different perspective and find new uses and meanings for them. The portfolio became a boundary object and obtained a hybrid meaning, shaped by the two activities which influenced its creation.

The importance of AT in understanding the nature of the portfolio and the portfolio texts is significant. These texts were created in the interaction of two activities and this would be a difficult result to reach without the parallel analysis of the activity systems. An AT analysis provided me with the tools to analyse the same texts as mediating means in one case (the workplace activity) and as activity objects in the other case (the qualification activity). This parallel examination led me to the question of what changed the use of these texts from mediating tools (workplace texts) to activity objects (portfolio texts). The concept of recontextualisation becomes clearer with an activity system analysis, as it makes it easier to understand not only why the use and the meaning of texts change but also what happens to them once they have changed. In this way, it becomes possible to study not only the trajectory of certain texts, but most importantly the historic development of literacy practices as they move from one activity system to the other. We follow literacy practices as they become robust boundary objects that can even penetrate new activities, they can change them and get changed by them and start, in this way, a new circle of recontextualisations.

\section{References}

Barton, D and Hamilton, M (2005) Literacy, Reification and the Dynamics of Social Interaction, in Barton, D and Tusting, K, eds, Beyond Communities of Practice: Language, power, and social context, Cambridge University Press, Cambridge.

Brandt, D (1995) Sponsors of Literacy, College Composition and Communication, vol 49, pp 165-185. 
Engeström, Y (1990) Learning, Working and Imagining: Twelve studies in activity theory, Orienta-Konsultit Oy, Helsinki.

Engeström, Y (2001) Expansive Learning at Work: Toward an activity theoretical reconceptualization, Journal of Education and Work, vol 14, no 1, pp 133-156.

Engeström, Y, Engeström, R and Kärkkäinen, M (1995) Polycontextuality and Boundary Crossing in Expert Cognition: Learning and problem solving in complex work activities, Learning and Instruction, vol 5, no 4, pp 319-336.

Fuller, A and Unwin, L (2004) Expansive Learning Environments: Integrating organizational and personal development, in Fuller, A, Munro, A and Rainbird, H, eds, Workplace Learning in Context, Routledge, London.

Gutierrez, K, Baquedano-Lopez, P and Tejeda, C (1999) Rethinking Diversity: Hybridity and hybrid language practices in the third space, Mind, Culture, and Activity, vol 6, no 4, pp 286-303.

Ivanič, R (2006) Language, Learning and Identification, in Kiely, R, ReaDickins, P, Woodfield, $\mathrm{H}$ and Clibbon, G, eds, Language, Culture and Identity in Applied Linguistics, BAAL \& Equinox Publishing Ltd, London, pp 7-29.

Kaptelinin, V (2005) The Object of Activity: Making sense of the sensemaker, Mind, Culture, and Activity, vol 12, no 1, pp 4-18.

Keating, M (2005) The Person in the Doing: Negotiating the experience of self, in Barton, D and Tusting, K, eds, Beyond Communities of Practice: Language, power and social context, Cambridge University Press, Cambridge.

Kell, C (2006) Crossing the Margins: Literacy, semiotics and the recontextualisation of meanings, in Pahl, $\mathrm{K}$ and Rowsell, J, eds, Travel Notes from the New Literacy Studies: Instances of practice, Multilingual Matters, Clevedon, pp 147-169.

Leontiev, A (1978) Activity, Consciousness and Personality, Prentice Hall, Englewood Cliffs, NJ.

Russell, D (2005) Texts in Contexts: Theorizing learning by looking at literacies, Paper presented at Seminar Two in the ESRC Teaching and Learning Research Programme (TLRP) thematic seminar series, Contexts, Communities, Networks: Mobilising learners' resources and relationships in different domains, Lancaster University.

Satchwell, C and Ivaniç, R (2007) The Textuality of Learning Contexts in UK colleges, Pedagogy, Culture and Society, vol 15, no 3, pp 303316.

Scribner, S (1997) Studying Literacy at Work: Bringing the laboratory to the field, in Tobach, E, Joffe-Falmagne, R, Parlee, M, Martin, L and Scribner-Kapelman, A, eds, Mind and Social Practice: Selected writings of Sylvia Scribner, Cambridge University Press, Cambridge. 
Star, S (1989) The Structure of Ill-Structured Solutions: Boundary objects and heterogeneous distributed problem solving, in Gasser, L and Huhns, M, eds, Distributed Artificial Intelligence, vol 2, Pitman, London, pp 37-54

Suchman, L (1994) Working Relations of Technology Production and Use, Computer Supported Cooperative Work, vol 2, pp 21-39.

Wenger, E (1998) Communities of Practice: Learning, meaning and identity, Cambridge University Press, Cambridge. 